\title{
Adaption and reliability of the Nutrition Environment Measures for stores (NEMS-S) instrument for use in urban areas of Chile
}

Gislaine Granfeldt ${ }^{1}$, Montserrat Victoriano ${ }^{1}$, Juan Antonio Carrasco ${ }^{2}$, Katia Sáez ${ }^{3}$, Maria del Mar Bibiloni ${ }^{4,5,6}$ and Josep A. Tur $4,5,6,7^{*}$

\begin{abstract}
Objective: To adapt and assess reliability of the Chilean version of Nutritional Environment Measurement for Stores (NEMS-S-CHILE) to measure the food environment of stores in urban areas.

Design: NEMS-S-CHILE was the NEMS-S tool adapted to the Chilean food patterns; foods were grouped according to level of processing in (a) unprocessed or minimally processed foods, (b) processed culinary ingredients, (c) processed foods, and (d) ultra-processed foods, and scored according to NEMS-S-CHILE tool. Reliability inter evaluators was measured.

Setting: City of Concepción, Bio-Bio region, Chile.

Participants: Seventeen of a total of 25 supermarkets, and 9 out of 10 street markets according to the municipal registry and the street market trade unions, representing 74.3\% of both types of food premises in Concepción.

Results: Reliability inter evaluators was measured by the following aspects: product availability, price, quality, and variety, through the intraclass correlation coefficient (ICC), percent agreement, and Cohen's kappa analysis. Reliability was high for availability, where the kappa index and ICC were acceptable, ranging from moderate to high (0.42 to 1.00 for the kappa coefficient and 0.65 to 1.00 for ICC), as well as for prices (ICC: 0.65-1.00), variety (kappa: 0.76-1.00) and quality (percent agreement: 68.2- 100\%).
\end{abstract}

Conclusions: The adapted instrument, NEMS-S-CHILE, has a high reliability inter evaluators and can be useful to measure the availability of foods by the level of processing according to the prevalent food system in developing countries.

Keywords: Chile, Food availability, Food environment, Food store survey

\section{Introduction}

The obesogenic environment, defined as "the built and dietary environment that affects patterns that lead to the

*Correspondence: pep.tur@uib.es

${ }^{7}$ Research Group on Community Nutrition and Oxidative Stress, University of the Balearic Islands, IDISBA \& CIBEROBN, Guillem Colom Bldg, Campus, E-07122 Palma de Mallorca, Spain

Full list of author information is available at the end of the article accumulation of "body fat", establishes obesity as the normal response of individuals to obesogenic environments in which they are found [1]. In the post-nutritional and demographic stage, Chile reaches the tenth place in the world among the countries with the highest obesity in adult population (74.2\%). Likewise, the country reaches the fifth place among the child population [2,3] with only $5 \%$ of the population feeding healthy [4]. The literature indicates that food consumption behavior is influenced by food environments that shape the decisions both 
family and individual [5-7]. These decisions affect quality and quantity of food consumed in the family diet and therefore, the intake of nutrients [8].

From the socio-ecological perspective, the study of retail food environment includes the community environment, widely studied through the density and proximity of types of premises available in the territory and the consumer environment, characterized by the availability of healthy foods, their price, and variety of options, freshness and nutritional qualities [8].

The constructs described to assess the food environment of consumers have generated many instruments based on food checklists that seek to capture environmental stimuli that can influence consumer food choices [9-11]. However, few instruments have undergone psychometric tests. The Nutritional Environment Measurement for Stores (NEMS-S) instrument [12], developed according to dietary guidelines of the North American population is aimed to collect information through the direct observation of categories and species of comparable foods in different retail stores, determining availability, quality, variety and price of the healthy food options. Its application has allowed guiding decision-making and it has been shown that has high reliability inter evaluators and apparent criterion validity [12, 13]. However, the retail food environments must be adapted to the contexts and cultural, food, ethnic and territorial contexts, and realities. Different versions of NEMS have been proposed, adapted according to representative dietary patterns of the population, adjusted to the reality of food supply chains available in each region or country [14-17]. Similarly, this is useful to observe among rural and urban areas [18, 19], ethnic populations [20] and other types of food stores $[13,16]$.

The retail food environment in Chile needs to be studied according to its specific characteristics. In addition to the differences in the nutritional and cultural patterns of the Chilean population, there are other differences in the distribution and sale models of food compared to developed countries. The "supermarket revolution" entered the markets strongly in the 2000's, though neighborhood stores and temporary food markets continue to play a leading role. This group of stores called street markets are an important marketing channel of the small and medium agriculture and artisanal fishing. These street markets supply $70 \%$ of fruits and vegetables and $30 \%$ of fish, which indicates the great importance of this channel for food security and the incomes of small producers and fishermen [21].

Food systems in low and middle-income countries have experienced a growing income in the intake of ultra-processed foods. In Chile, its consumption reaches $28.6 \%$ of the total energy intake, with more than half of the total intake of added sugars. In addition, the absolute expense in ultra-processed foods has increased in $110 \%$ [22, 23]. These industrial formulations of food and beverages are produced mainly by refined substances extracted or derived from foods and additives [24, 25]. The evidence is categorical by stating that its consumption is associated with imbalances in nutrient intake and the incidence of cardiovascular diseases, displacing dietary patterns based on minimally processed or natural foods and fresh foods [26-29]. Since 2016, Chile has its own Law regulating nutritional food composition and its advertising [30].

Consequently, the objective of this study was to adapt and assess the reliability inter evaluators of the Chilean version of the Survey of Nutritional Environment Measures in (NEMS-S-CHILE) Stores in the city of Concepcion's urban context.

\section{Methods}

This work is part of a larger study, aimed to assess the role of the mobility of different people according to their eating patterns in the city of Concepcion's urban context of Chile. The current research was carried out in MarchMay 2018 in the commune of Concepción, capital of the Bio-Bio Region, with a population of 219,057 inhabitants, and $221.6 \mathrm{~km}^{2}$ of area [31].

\section{Sample Selection}

The sample selection was performed by convenience, selecting 17 out of a total of 25 supermarkets according to the information provided in the patent office of the municipality of Concepción, and 9 out of 10 street markets according to the municipal registry and the street market trade unions, representing $74.3 \%$ of both types of food premises in the commune of Concepción. The application of the instrument in convenience stores or neighborhood businesses, butchers, bakeries, or candy stores was not considered in the development of the project. The instrument was applied after the explicit authorization of the owners and/or administrators of the premises, without prior contact. A cover letter was extended to the local manager explaining the details of the study and answering any potential queries about the process. To assess reliability, inter evaluator, the instrument was applied twice on the same day.

\section{NEMS-S-CHILE}

The original NEMS-S tool was designed to audit the retail store environment through direct observation allowing knowing the food environment of the consumers, through availability, quality, variety, and price of healthy food options in eleven food categories: milk, fruit, vegetables, ground beef, hot dogs, frozen meals, 
bakery, beverages, bread, potato chips and cereals. Many of these foods are not available or are not part of the cultural and food reality of other populations.

To adapt this tool to the Chilean context, a consensus was achieved in the research team made up of a sociologist, an engineer, a dietitian as well as two external dietitians who were members of the Healthy Life Center of the University of Concepción. The instrument was translated into Spanish, evaluating relevance and clarity of contents, and then adapted through three steps: (a) the selection of foods suitable to the Chilean culture, (b) the classification according to the level of food processing, and (c) adjusting a scoring system according to the availability, price, variety, and quality of food (see Supplementary material S1).

(a) The food selection was performed in accordance with the Family Budget Survey [22], the National Survey of Food Consumption 2011 [4] and the dietary guidelines for the Chilean population [32, 33]. This survey represents the balance energy and identifies healthy foods for daily consumption, as well as critical nutrients for the Chilean population. The representation listed in descending order includes fruits and vegetables, dairy products, meats, legumes and eggs, grains, and oils.

(b) The foods were selected according to the level of industrial processing. For this purpose, the NOVA (it is not an acronym) classification by Monteiro et al. $[24,25]$ was applied. This classification groups foods that were classified according to the nature, scope, and purpose of their industrial processing. This classification divides foods into 4 groups:

Group 1: Natural or minimally processed foods, which includes the removal of inedible or unwanted parts, and drying, grinding, fractionation, filtering, roasting, boiling, non-alcoholic fermentation, pasteurization, refrigeration, cooling, freezing, storage in containers, and vacuum packed.

Group 2: Culinary ingredients, which are substances derived from Group 1 or natural foods through processes that include pressing, refining, grinding, and drying.

Group 3: Processed foods that have two or three ingredients and are recognizable as modified versions of Group 1 foods.

Group 4: Ultra-processed foods, including hydrogenation and hydrolyzation, extrusion and molding, as well as pre-processing for frying, in addition to the use of additives such as preservatives, antioxidants, and stabilizers.

\section{Score}

The scoring system was modified from the original version based on the level of industrial food processing. In the original version of NEMS-S, a higher score was assigned to the healthy option low in calories, fats, and sugars. On the other hand, the NEMS-S-CHILE version where a food was considered unhealthy if it was ultraprocessed, regardless of whether its composition has been modified to reduce sugar or fat content or increase fiber. The Chilean version includes 62 foods, subdivided into 27 measures, distributed in four groups according to the processing level, evaluating the availability, price, variety, and quality of the foods (Table 1). Regarding availability, Group 1 foods were considered "healthier", Groups 2 and 3 "intermediate" and Group 4 "unhealthy". Groups 1, 2 and 3 obtained positive points, concentrating the highest score in Group 1 for being natural or minimally processed products. Group 4 foods received negative points, setting a difference compared to the original NEMS-S which gives a positive score to ultra-processed foods low in calories, fat, and sugar.

Regarding prices, an additional score was assigned to compare monetary values. Similarly, an additional score was assigned for the same amounts of foods based on NOVA categories. The variation in the price of fruits and vegetables was not considered, due to the spatial characteristic of street markets and the difficulty in unifying the unit of measurement in the sales format.

The quality was determined for each fresh fruit and vegetable like NEMS-original. It was qualified as "adequate in quality" if more than $75 \%$ of each food reached the maximum condition according to its organoleptic characteristics (color, freshness, texture, and cleanliness). Accordingly, 3 additional points were assigned if more than $75 \%$ of the total fruits and vegetables complied with the concept of "adequate quality", 2 points if they reached between $74 \%$ and $50 \%$ of each food, 1 point if they reached between $49 \%$ and $25 \%$ and 0 points if less than $25 \%$ met the requirement.

The variety was determined for fruits and vegetables as NEM-S, and the variety of legumes was incorporated (a food not included in the original instrument), assigning extra-scores in those premises that presented additional varieties not contemplated in the instrument. If fruits and vegetables had more than 3 additional varieties, 3 points were added to each measure. In the case of legumes, 4 additional points were assigned if there were more than 5 varieties.

Finally, scores were awarded to each food measurement, according to the previous conditions; reaching scoring ranges between -30 and 100 points compared to -8 and 50 in the original NEMS-S (see Supplementary material S2). In both versions, the highest total score per 
Table 1 Food measurements and scoring dimensions in the Chile version of the Food Environment Measurement Survey for Stores (NEMS-CHILE)

\begin{tabular}{|c|c|c|c|c|}
\hline Type of food & Availability & Quality & $\begin{array}{l}\text { Comparative } \\
\text { price }\end{array}$ & Variety \\
\hline \multicolumn{5}{|c|}{ GROUP 1: Natural or minimally processed foods } \\
\hline Fresh fruits & $x$ & $x$ & & $x$ \\
\hline Fresh vegetables & $x$ & $x$ & & $x$ \\
\hline Lean meat & $x$ & & & \\
\hline Chicken & $x$ & & & \\
\hline Fresh sea products & $x$ & & & \\
\hline Legumes & $x$ & & & $x$ \\
\hline Oleaginous fruits & $x$ & & & \\
\hline Potato & $x$ & & & \\
\hline Rice & $x$ & & $x$ & \\
\hline Liquid milk & $x$ & & $x$ & \\
\hline \multicolumn{5}{|c|}{ GROUP 2: Processed culinary ingredients } \\
\hline Oil & $x$ & & $x$ & \\
\hline Butter & $x$ & & & \\
\hline Wheat flour & $x$ & & $x$ & \\
\hline \multicolumn{5}{|c|}{ GROUP 3: Processed foods } \\
\hline Canned seafood & $x$ & & & \\
\hline Yogurt & $x$ & & $x$ & \\
\hline Dried noodles & $x$ & & $x$ & \\
\hline Wholemeal bread & $x$ & & $x$ & \\
\hline $\begin{array}{l}\text { Cheeses and deriva- } \\
\text { tives }\end{array}$ & $x$ & & $x$ & \\
\hline $\begin{array}{l}\text { Processed oleaginous } \\
\text { fruits }\end{array}$ & $x$ & & & \\
\hline \multicolumn{5}{|c|}{ GROUP 4: Ultra-processed food products } \\
\hline Sausages & $x$ & & & \\
\hline Jams & $x$ & & & \\
\hline $\begin{array}{l}\text { Soda (carbonated } \\
\text { drinks) }\end{array}$ & $x$ & & & \\
\hline Juices & $x$ & & & \\
\hline Processed fat & $x$ & & & \\
\hline Breakfast cereals & $x$ & & & \\
\hline Biscuits & $x$ & & & \\
\hline White bread & $x$ & & & \\
\hline
\end{tabular}

$X$ Score dimensions

grocery store refers to the highest availability of healthy foods versus the lowest score.

\section{Training}

The evaluators corresponded to two dietitians invited to participate in the project. They were trained to collect data, field practices, typing and scoring. They were provided with an instruction manual. Preliminary tests were carried out in four premises and minimal corrections were made to the instrument to facilitate its application, clarifying units of measurements and food formats to audit.

\section{Statistical analysis}

All data analyses were performed with the SPSS $^{\circledR}$ version 24.0 statistical program (IBM Corporation New York, NY, USA). To analyze the reliability inter evaluators in the aspects of availability, quality and variety, the percentage of general agreement and Cohen's Kappa coefficient (k) were determined for dichotomous measures (yes/ no). A Kappa values between 0 and 0.2 indicated a mild agreement, 0.21-0.40 fair agreement, 0.41-0.60 moderate agreement, 0.61-0.80 substantial agreement and between 0.81 and 1.00 perfect agreement [34]. For price comparisons, the analyses included only prices for the same type, size, and brand than that of the studied product and the intraclass correlation coefficient (ICC) was determined. An ICC value of $<0.4$ was considered as bad agreement, 0.41-0.59 as regular agreement, $0.60-0.74$ as good agreement and $>0.75$ as excellent agreement [35] .

\section{Results}

The instrument was applied in 17 supermarkets and 9 street markets. These represented $74.6 \%$ of the stores of this type in the studied areas. The average application time to the instrument was $60 \mathrm{~min}$ for supermarkets and $80 \mathrm{~min}$ for street markets, due to their territorial extension.

Table 2 shows the findings for the reliability inter evaluators of food classified by group, according to the processing level. The percentage of agreement for reliability was extremely high, with a range between $84.6 \%$ and $100 \%$. For the Kappa analysis of the 30 food items studied, 24 of them reached a perfect agreement (0.81-1.00), 4 reached a substantial agreement (0.61-0.80), and 2 obtained a moderate agreement $(0.41-0.60)$.

Table 3 shows the reliability inter evaluators for the fresh fruits and vegetables, according to the products' availability and quality. The percentages of agreement inter evaluators for availability (88.5-100\%) and quality (75-100\%) were extremely high, except for avocados, which reached a high level of agreement (68\%). Kappa statistic for most fruits and vegetables was low or could not be calculated due to the high proportion of acceptable quality, or in some cases, due to lower availability of food present in stores, such as kiwi, tangerine, pear, and celery.

Table 4 shows the reliability inter evaluators for availability, variety and price. The level of agreement for availability was extremely (80.8-100\%), and the Kappa statistic showed a perfect agreement in all products analyzed, except for mature cheese. In the price, the ICC showed a high level of agreement (0.75-1.00), 
Table 2 Reliability measures inter evaluators in all groups of food

\begin{tabular}{|c|c|c|}
\hline \multirow[b]{2}{*}{ Type of food } & \multicolumn{2}{|c|}{$\begin{array}{l}\text { Reliability inter } \\
\text { evaluators }\end{array}$} \\
\hline & Kappa & $\%$ Agreement \\
\hline \multicolumn{3}{|c|}{ GROUP 1: Natural or minimally processed foods } \\
\hline Fruit fresh & 0.87 & 96.15 \\
\hline vegetables fresh & 1.00 & 100 \\
\hline Lean meat & 0.92 & 96.15 \\
\hline Chicken & 0.91 & 96.15 \\
\hline Egg & 0.65 & 96.15 \\
\hline Fish & 0.92 & 96.15 \\
\hline Seafood & 0.84 & 92.31 \\
\hline Legumes & 1.00 & 100 \\
\hline Oleaginous fruits & 0.84 & 96.15 \\
\hline Potato & 1.00 & 100 \\
\hline Rice & 1.00 & 100 \\
\hline Milk fluid & 1.00 & 100 \\
\hline \multicolumn{3}{|c|}{ GROUP 2: Processed culinary ingredients } \\
\hline Oil & 0.70 & 92.31 \\
\hline Butter & 1.00 & 100 \\
\hline Wheatflour & 1.00 & 100 \\
\hline \multicolumn{3}{|l|}{ GROUP 3: Processed foods } \\
\hline Canned fish & 0.70 & 92.31 \\
\hline Canned seafood & 0.91 & 96.15 \\
\hline Yogurt & 1.00 & 100 \\
\hline Dried noodles & 1.00 & 100 \\
\hline Wholemeal bread & 0.84 & 92.31 \\
\hline Cheeses and derivatives & 0.42 & 84.62 \\
\hline Processed oleaginous fruits & 0.43 & 84.62 \\
\hline \multicolumn{3}{|c|}{ GROUP 4: Ultra-processed food products } \\
\hline Sausages & 0.90 & 96.15 \\
\hline Jams & 1.00 & 100 \\
\hline Soda (carbonated drinks) & 1.00 & 100 \\
\hline Juices & 1.00 & 100 \\
\hline Processed fat & 1.00 & 100 \\
\hline Breakfast cereals & 0.78 & 92.31 \\
\hline Biscuits & 1.00 & 100 \\
\hline White bread & 1.00 & 100 \\
\hline
\end{tabular}

Reliability inter evaluators through food availability (yes/no) was examined using the kappa coefficient

except for white rice, ripe cheese, and whole yogurt, which reached a good agreement $(0.65-0.70)$. In the price comparison, the healthy options presented a smaller proportion than the regular ones, as is the case with brown rice, olive oil, whole wheat flour, whole wheat noodles, whole wheat bread, and cheese. In relation to extra variety, both percentages of agreement $(92.3-100 \%)$ and kappa statistic $(0.76-1.00)$ were exceedingly high.
Table 3 Reliability measurements inter evaluators for product availability and quality

\begin{tabular}{|c|c|c|c|c|c|}
\hline \multirow[b]{2}{*}{ Product } & \multicolumn{2}{|c|}{ Availability } & \multicolumn{3}{|c|}{ Quality } \\
\hline & Kappa & $\%$ Agreement & $n$ & Kappa & $\%$ Agreement \\
\hline FRUITS & 0.87 & 96.2 & - & - & - \\
\hline Kiwi & 0.91 & 96.20 & 18 & 0.45 & 88.9 \\
\hline Tangerine & 1.00 & 100 & 18 & 0.47 & 83.3 \\
\hline Apple & 1.00 & 100 & 21 & - & 100 \\
\hline Orange & 0.78 & 92.3 & 19 & - & 78.9 \\
\hline Pear & 1.00 & 100 & 18 & - & 100 \\
\hline Banana & 0.88 & 96.2 & 20 & - & 75.0 \\
\hline VEGETABLES & 1.00 & 100 & - & - & - \\
\hline Cerely & 0.72 & 88.5 & 17 & - & 100 \\
\hline Chard & 0.87 & 96.2 & 21 & - & 100 \\
\hline Lettuce & 1.00 & 100 & 22 & - & 100 \\
\hline Onion & 1.00 & 100 & 22 & - & 100 \\
\hline Avocado & 1.00 & 100 & 22 & - & 68.2 \\
\hline Pepper & 1.00 & 100 & 22 & - & 100 \\
\hline Cabbage & 1.00 & 100 & 20 & - & 100 \\
\hline Tomato & 1.00 & 100 & 22 & - & 100 \\
\hline Carrot & 1.00 & 100 & 21 & - & 95.2 \\
\hline
\end{tabular}

Consistency inter evaluators of food availability (yes/no) and food quality (yes/ no) was examined through kappa coefficient. Fields with dashes indicate that statistics could not be calculated due to $<2$ levels/cross tabulation

Table 5 shows the comparison between stores per food group. No significant differences were observed in Group 1 among stores. This group was composed of natural or minimally processed foods. However, the average score was higher for fruits and vegetables in street markets. In groups 2, 3 and 4 there were significant differences because supermarkets presented a greater amount of processed and ultra-processed foods. In the total score, street markets present higher average score than supermarkets.

\section{Discussion}

This work constitutes the first version of a tool to measure the food environment in Chile, adapted from the original NEMS-S to Chilean context, to assess the food availability. Similarly, the eating and cultural context of the country was also considered.

NEMS-S is considered an environmental audit tool, based on observation, whose consistency is determined by reliability inter evaluators, reaching high ranges of reliability in most versions of NEMS-S, original and adapted (Brazil, China, Spain, and Canada), which clarifies that the measurement protocol and training methods are sufficient to prepare the interviewers in data collection process with high precision. For original NEMS-S, the kappa coefficient between evaluators varied from 0.83 to 1.00 
Table 4 Reliability measurement inter evaluators for price and variety of products

\begin{tabular}{|c|c|c|c|c|c|c|}
\hline & \multicolumn{2}{|c|}{ Availability $^{\mathrm{a}}$} & \multicolumn{2}{|c|}{ Price $^{b}$} & \multicolumn{2}{|c|}{ Variety $^{\mathrm{a}}$} \\
\hline & Kappa & $\%$ Agreement & $n$ & ICC & Kappa & $\%$ Agreement \\
\hline \multicolumn{7}{|l|}{ Rice } \\
\hline White & 0.84 & 96.2 & 18 & 0.7 & - & - \\
\hline integral & 0.91 & 96.2 & 14 & 1 & - & - \\
\hline \multicolumn{7}{|l|}{ Liquid milk } \\
\hline Whole & 1 & 100 & 18 & 0.99 & - & - \\
\hline Skim & 1 & 100 & 18 & 1 & - & - \\
\hline \multicolumn{7}{|l|}{ Oil } \\
\hline Olive & 0.82 & 92.3 & 12 & 1 & - & - \\
\hline Sunflower & 1 & 100 & 14 & 0.76 & - & - \\
\hline Vegetable & 0.87 & 96.2 & 13 & 0.76 & - & - \\
\hline \multicolumn{7}{|l|}{ Wheat flour } \\
\hline White & 1 & 100 & 17 & 0.96 & - & - \\
\hline Integral & 1 & 100 & 12 & 0.99 & - & - \\
\hline \multicolumn{7}{|l|}{ Yogurt } \\
\hline Whole & 1 & 100 & 14 & 0.65 & - & - \\
\hline Skim & 1 & 100 & 16 & 1 & - & - \\
\hline \multicolumn{7}{|l|}{ Dried noodles } \\
\hline White & 0.84 & 96.2 & 21 & 0.75 & - & - \\
\hline Integral & 0.84 & 92.3 & 11 & 0.99 & - & - \\
\hline \multicolumn{7}{|l|}{ Wholemeal bread } \\
\hline Bread shake & 0.92 & 96.2 & 10 & 0.76 & - & - \\
\hline Mold integral & 0.84 & 96.2 & 7 & 0.94 & - & - \\
\hline \multicolumn{7}{|l|}{ Cheese and derivatives } \\
\hline Mature cheese & 0.33 & 80.8 & 15 & 0.70 & - & - \\
\hline Quesillo & 0.78 & 92.3 & 11 & 0.89 & - & - \\
\hline Other extra fruits & - & - & - & - & 0.80 & 92.3 \\
\hline Other extra fresh vegetables & - & - & - & - & 0.76 & 92.3 \\
\hline Other extra legumes & - & - & - & - & 1 & 100 \\
\hline
\end{tabular}

Abbreviations: ICC intraclass correlation coefficient

${ }^{a}$ The consistency inter evaluators of food availability (yes/no) and the variety of food (yes / no) was examined using the kappa coefficient

${ }^{b}$ The degree of price consistency inter evaluators was examined by the ICC

Fields with dashes indicate that statistics could not be calculated due to $<2$ levels/cross tabulation

Table 5 Comparison of NEMS-S-CHILE scores between food stores

\begin{tabular}{|c|c|c|c|c|c|c|c|c|c|c|c|}
\hline & \multicolumn{5}{|c|}{ Street markets } & \multicolumn{5}{|c|}{ Supermarket } & \multirow[b]{2}{*}{$P$ value } \\
\hline & Mean & SD & Median & Q1 & Q3 & Mean & SD & Median & Q1 & Q3 & \\
\hline Group 1 & 53.6 & 8.6 & 56 & 50 & 58 & 52.9 & 17.4 & 62 & 40 & 62 & 0.385 \\
\hline Fruits and vegetables & 26.2 & 4.6 & 28 & 27 & 28 & 20.5 & 11.9 & 28 & 11 & 28 & 0.406 \\
\hline Other foods G1 & 27.3 & 5.2 & 28 & 22 & 30 & 32.4 & 6.6 & 34 & 29 & 34 & 0.051 \\
\hline Group 2 & 1.4 & 2.0 & 1 & 0 & 2.5 & 7.5 & 0.9 & 8 & 7 & 8 & $<0.001$ \\
\hline Group 3 & 4.1 & 3.0 & 5 & 1 & 6.5 & 12.1 & 1.3 & 13 & 12 & 13 & $<0.001$ \\
\hline Group 4 & 3.3 & 3.7 & 2 & 0 & 6 & 29.4 & 1.4 & 30 & 29 & 30 & $<0.001$ \\
\hline Total & 55.8 & 9.6 & 59 & 51 & 62 & 43.2 & 17.7 & 51 & 31 & 53 & 0.032 \\
\hline
\end{tabular}

SD Standard Deviation 
[12], for the Brazilian version the kappa coefficient varied from 0.69 to 1.00 and the ICC from 0.75 to 1.00 [14]. Current NEMS-S-CHILE version showed results like NEMS-CHINA [15], where the kappa index and the ICC were acceptable, varying from moderate to high ( 0.42 to 1.00 for kappa coefficient and 0.65 to 1.00 for ICC).

The reliability inter evaluators measures for availability, according to the food groups studied by processing levels, were high in practically all categories evaluated. However, Group 3 of processed foods presented moderate concordance in mature cheese and nuts (0.42-0.43). A similar situation was observed in other instruments where product packaging, diversity of nutritional labels and healthy descriptors are illegible, making it difficult to understand these foods $[15,17,36]$.

When analyzing the quality of food through organoleptic characteristics, mainly fruits and vegetables trained personnel are required to determine sensory parameters for the qualitative evaluation of products. In addition, in Chile, products such as fresh fruits and vegetables are mostly bought at the street market. The conditions of sale are outdoors and at room, which could generate differences in the classification of quality or freshness by limiting the choice of food. However, in this study, most of the fruits and vegetables reached a high percentage of agreement among the pollsters. The exception is the avocado (68.2\%), since it is a food whose quality is subjective and highly variable because the damage mechanics, frictions and punctures that affect quality, vascular darkening, consumption maturity, and basal rot, which are not always reflected in the external appearance of the fruit [37, 38]. In relation to groups 2,3 and 4 , as the level of processing increases, the availability of these foods is greater in supermarkets than in street market.

The price difference between healthy and regular options has been studied with increasing attention in recent years [39-41]. The availability of healthy options could be influenced by the type of store, size, and rurality, and the healthy version of food can be more expensive than the less healthy or regular version.

The differentiating approach of this study is framed on the food classification according to the degree of processing, providing relevance in the score assignment to those foods in the natural or minimally processed state. This differs from the original version [12] and another adapted versions [15-17]. In this case, the focus is on the availability of healthier options, prioritizing the low intake of calories and fat, in some cases with a high degree of industrial processing. In Latin America, the eating patterns have changed dramatically, especially in recent years, influenced by the commercial opening to foreign investment, without market regulation in many cases [25]. In Chile, the supply of food to increasingly urban consumers is characterized by a high penetration of supermarket chains, decreasing the purchase in street markets [21]. This is accompanied by extensive communication and food promotion campaigns of processed food, high in levels of critical nutrients (sugar, fats, and salt). In this way, in the Latin American region, Chile and Mexico are the first consumers of ultra-processed products, consumption that is double than that of other countries in the region such as Brazil (where an adaptation of the original NEMS has already been validated. Thus, specific validation would be required, including processing level as classification.

That process has led to a shift in the eating patterns in low and middle-income countries, where the consumption of ready meals from unprocessed or minimally processed foods has changed to ultra-processed products with excessive caloric density, high in free sugars, unhealthy fats, and salt, as well as low in dietary fiber. From this perspective, the evidence is clear when establishing the risk of consuming ultra-processed foods in the increase of body weight and the appearance of cardiovascular diseases, as previous works point out [23, 27, 42].

Therefore, determining the availability of these foods could guide the association between access, availability, and epidemiological trends, as well as promoting the progress of improvement initiatives for the design of food environments in the community.

Laws 20.606 and 20.869 were established on 2012 and 2015, respectively, about the nutritional components of food and its publicity $[44,45]$. It establishes a proper labeling, which is regulated by the Chilean Food Health Regulations. It must contain clear information; therefore, the population can easily understand at least regarding the content of energy, sugar, salt, and fat. It establishes the shape of the warning labeling according to the law: It is by labeling an octagonal symbol with a background black and white border, and within the text "HIGH" followed by "Saturated Fat", "Sodium", "Sugars" or "Calories". Therefore, foods without warning labeling are still ultraprocessed products, that is, they are made with less sugar or salt or fat, but they maintain their original formulas, characterized by the incorporation of by-products of other ingredients such as starches, protein concentrates, flavorings, stabilizers, colorants, and other components. The latter would also be associated with the NOVA classification.

Warning labeling was thought of as a strategy to improve selection, but it is not the solution to the obesity epidemic. Since changes in eating patterns must be accompanied by food education and revaluation of traditional food. In addition, strategies must be developed that facilitate access to fresh food at affordable prices and guaranteeing local production models. 
A limitation that the labeling law has brought is that the industry has modified the ingredients of the food, so as not to carry logos. However, the health effects are still those attributable to ultra-processed products, which also have a high level of satiety and low cost.

Finally, regional differences in availability and prices of food have been pointed out [43]. Like previous papers of NEMS adaptations in other countries [14, 15, 20], the selected geographic area corresponds to a metropolitan sector. In this case, the city of Concepción is a representation of the retail trade and the agri-food reality of Chile. Within the commercial perimeter, where much of the trade is concentrated, and many people are mobilized, the high reliability obtained in the application of the instrument allows it to be applied in different territorial realities, and therefore to establish differences in the consumer's food environment according to geographical location. However, since the current study was carried out in just the region of Bio-Bio, it is encouraged that further studies analyze differences between Chilean regions.

\section{Strengths and limitations}

Regarding the strengths of the study, the interviewers corresponded to dietitians closely related to the identification of foods, varieties, and quality determination, which facilitates the application of this instrument. However, the adequate training could bring the technical skills and competencies necessary for the application of the instrument, without being a professional in the discipline. On the other hand, the instrument could be applied in supermarkets and street markets twice the same day without impediments. The kappa statistical analysis to determine the availability of a product, and the ICC to determine the level of agreement between the qualifications of the evaluators, allowed to include quality, variety, and price of food within the score. The results obtained with this methodology allowed contributing to a more complete instrument, to be applied in food stores.

The study, however, has also several limitations. First, the instrument was validated in the Province of Concepción metropolitan area, and there may be differences in the socioeconomic level and population density, which could influence the availability of food according to place. In addition, a convenience sample from supermarkets and street markets was used to measure adaptation and reliability of NEMS-S-CHILE at this stage of the project.

Second, the list of foods studied according to the level of processing, may vary depending on the seasonality and geographical distribution of the country, which implies that some foods are not available throughout the national territory. Another limitation of this work is that results cannot be extrapolated to convenience stores or especially food store environments, as these were not evaluated in this project, however, this work provides a basis for further field work. The current study was carried out in just a region of Chile, and not in extreme regions; then, the variability in availability and prices of food among regions was not evaluated, and it constitutes another limitation to be solved in future studies.

Finally, it was not possible to calculate kappa for quality due to the high proportion of acceptable quality and, in some cases, due to the low availability of food present in stores. This latter result may be influenced by the day of supply of the different places of sale, conditioned by its availability every day. However, the NEMS-S-CHILE was carried out according to the Family Budget Survey, the National Survey of Food Consumption 2011, and the Food Based Food Guidelines of Chile, which have country wide representation.

\section{Conclusions}

The adapted instrument, NEMS-CHILE, has high reliability inter evaluators and it can be useful to measure food availability, food environment and favor health intervention actions in the Chilean context. In this study, the food classification is according to the degree of processing, which differs from the original version, seems to be more in line with the food systems of developing countries where the prevalence of chronic diseases is associated with the consumption of ultra-processed as in Chile. This study is the first adaptation in Chile to understand the consumer food environment.

\section{Abbreviations}

ICC: intraclass correlation coefficient; NEMS-S: The Nutritional Environment Measurement for Store; NEMS-S-CHILE: Chilean version of the Nutritional Environment Measurement for Stores; NEMS-CHINA: Chinese version of the Nutritional Environment Measurement for Stores.

\section{Supplementary Information}

The online version contains supplementary material available at https://doi. org/10.1186/s12889-022-12651-w.

Additional file 1.

\section{Acknowledgements}

Center of Healthy Life of the University of Concepción, Chile, for its contribution to the development of the instrument. Pablo Allende and pollsters who applied the instrument.

\section{Authors' contributions}

GGM and MMB designed the study and wrote the protocol; GGM, MVR, JAC and KSC collected samples; KSC and MMB conducted the statistical analysis; GGM, MMB and JAT wrote the first draft of the manuscript. All authors read and approved the final manuscript.

\section{Funding}

Project FONDECYT 1171113. MMB and JAT were funded by the Institute of Health Carlos III through the Health Research Fund (FIS), co-funded by the European Regional Development Funds (ERDF), through projects PI17/01827 
and PI20/00456, Red Predimed-RETIC RD06/0045/1004, and CIBEROBN (CB12/03/30038), as well as support for competitive research groups 35/2011 of the Government of the Balearic Islands, the EU-COST Program (COST Action CA16112) and aid from the Health Research Institute of the Balearic Islands, IDISBA (PRIMUS, SYNERGIA, LIBERI). The funding sponsors had no role in the design of the study, in the collection, analyses, or interpretation of the data; in the writing of the manuscript, or in the decision to publish the results.

\section{Availability of data and materials}

There are restrictions on the availability of data for this trial, due to the signed consent agreements around data sharing, which only allow access to external researchers for studies following the project purposes. Requestors wishing to access the trial data used in this study can make a request to pep.tur@uib.es.

\section{Declarations}

\section{Ethics approval and and consent to participate}

The application of the NEMS-CHILE instrument did not need ethical approval because no human subjects were included in data collection. However, this study was conducted according to the guidelines laid down in the Declaration of Helsinki and all procedures involving research study participants were presented to and approved by the Ethics and Biosafety Committee of the University of Concepción, Chile, in June 2017 (ref. NEMS/2017). Informed consent was obtained from all subjects.

\section{Consent for publication}

The results and writing of this manuscript followed the Committee on Publication Ethics (COPE) guidelines on how to deal with potential acts of misconduct, maintaining integrity of the research and its presentation following the rules of good scientific practice, the trust in the journal, the professionalism of scientific authorship, and the entire scientific endeavor. This manuscript does not contain any individual person's data in any form (including any individual details, images, or videos).

\section{Competing interests}

None of the authors report having conflicts of interest.

\section{Author details}

${ }^{1}$ Department of Nutrition and Dietetics, Faculty of Pharmacy, University of Concepción, Concepción, Chile. ${ }^{2}$ Department of Civil Engineering, Faculty of Engineering, University of Concepción, Concepción, Chile. ${ }^{3}$ Faculty of Physical Sciences and Mathematics, Department of Statistics, University of Concepción, Concepción, Chile. ${ }^{4}$ Research Group on Community Nutrition and Oxidative Stress, University of the Balearic Islands-IUNICS, E-07122 Palma de Mallorca, Spain. ${ }^{5}$ Institute of Health Carlos III, CIBEROBN (Physiopathology of Obesity and Nutrition, CB12/03/30038), E-28029 Madrid, Spain. ${ }^{6}$ Health Research Institute of the Balearic Islands (IDISBA), E-07120 Palma de Mallorca, Spain. ${ }^{7}$ Research Group on Community Nutrition and Oxidative Stress, University of the Balearic Islands, IDISBA \& CIBEROBN, Guillem Colom Bldg, Campus, E-07122 Palma de Mallorca, Spain.

Received: 24 July 2021 Accepted: 16 December 2021

Published online: 03 February 2022

\section{References}

1. Swinburn BA, Sacks G, Hall KD, et al. The global obesity pandemic: shaped by global drivers and local environments. Lancet 2011;378(9793):804-814.

2. NCD Risk Factor Collaboration (NCD-RisC). Worldwide trends in bodymass index, underweight, overweight, and obesity from 1975 to 2016: a pooled analysis of 2416 population-based measurement studies in 12809 million children, adolescents, and adults. Lancet 2017. Published online October 10, 2017

3. Vio del Rio F. Aumento de la obesidad en chile y en el mundo. Rev Chil Nutr 2018;45(1):6.

4. Universidad de Chile. Encuesta Nacional de Consumo Alimentario: Informe final. Santiago, Chile: Universidad de Chile; 2011; p. 329. Available at: http://web.minsal.cl/sites/default/files/ENCA-INFORME_FINAL.pdf
5. M de Freitas PP, de Menezes MC, Lopes ACS. Consumer food environment and overweight. Nutrition 2019;66:108-114.

6. Kelly C, Callaghan M, Molcho M, et al. Food environments in and around post-primary schools in Ireland: Associations with youth dietary habits. Appetite 2019;132:182-189.

7. Kaji A, Hashimoto Y, Sakai R, et al. Frequent Usage of Convenience Stores is Associated with Low Diet Quality. Nutrients 2019;11(6):1212.

8. Caspi CE, Sorensen G, Subramanian SV, et al. The local food environment and diet: a systematic review. Health Place 2012;18(5):1172-1187

9. Ohri-Vachaspati P, Leviton LC. Measuring Food Environments: A Guide to Available Instruments. AJHP 2010;24(6):410-426.

10. Lytle LA, Sokol RL. Measures of the food environment: A systematic review of the field, 2007-2015. Health Place 2017:44:18-34.

11. Glanz K, Johnson L, Yaroch AL, et al. Measures of Retail Food Store Environments and Sales: Review and Implications for Healthy Eating Initiatives. J Nutr Educ Behav 2016;48(4):280-288.e281.

12. Glanz K, Sallis JF, Saelens BE, et al. Nutrition Environment Measures Survey in stores (NEMS-S): development and evaluation. Am J Prev Med 2007;32(4):282-289.

13. Saelens BE, Glanz K, Sallis JF, et al. Nutrition Environment Measures Study in restaurants (NEMS-R): development and evaluation. Am J Prev Med 2007;32(4):273-281.

14. Martins PA, Cremm EC, Leite FH, et al. Validation of an adapted version of the nutrition environment measurement tool for stores (NEMS-S) in an urban area of Brazil. J Nutr Educ Behav 2013;45(6):785-792.

15. Liu Y, Song S, Gittelsohn J, et al. Adaptation and Validation of the Chinese Version of the Nutrition Environment Measurement Tool for Stores. Int J Environ Res Public Health 2019;16(5):782.

16. Carins JE, Rundle-Thiele S, Storr RJ. Appraisal of short and long versions of the Nutrition Environment Measures Survey (NEMS-S and NEMS-R) in Australia. Public Health Nutr 2019:22(3):564-570.

17. Borges CA, Jaime P. Development and evaluation of food environment audit instrument: AUDITNOVA. Rev. saúde pública 2019;53:91

18. Ko LK, Enzler C, Perry CK et al. Food availability and food access in rural agricultural communities: use of mixed methods. BMC Public Health 2018;18:634.

19. Shikany J, Carson T, Hardy C, et al. Assessment of the nutrition environment in rural counties in the Deep South. J Nutr Sci 2018;7:E27.

20. Lo BK, Minaker LM, Mah CL, et al. Development and Testing of the Toronto Nutrition Environment Measures Survey-Store (ToNEMS-S). J Nutr Educ Behav 2016;48(10):723-729.

21. FAO/ODEPA/ASOF, Observatorio Feria Libre: "Características Económicas y Sociales de Ferias Libres de Chile"Encuesta Nacional de Ferias Libres, abril 2013

22. Instituto Nacional de Estadísticas. VIII Encuesta de presupuestos familiares. Santiago, Chile: Instituto nacional de Estadísticas; 2017-2018. Available at: http://www.ine.cl/epf

23. Cediel G, Reyes M, da Costa Louzada ML, et al. Ultra-processed foods and added sugars in the Chilean diet (2010). Public Health Nutr 2018;21(1):125-133.

24. Monteiro CA, Cannon G, Moubarac JC, et al. The UN Decade of Nutrition, the NOVA food classification and the trouble with ultra-processing. Public Health Nutr 2018:21(1):5-17.

25. Pan American Health Organization of the World Health Organization. Ultra-Processed Food and Drink Products in Latin America: Trends, Impact on Obesity, Policy Implications. Washington, DC: PAHO; 2015. Available at http://iris.paho.org/xmlui/bitstream/handle/123456789/7699/97892 75118641_eng.pdf? sequence $=5$ \&isAllowed $=y \& u a=1$.

26. Monteiro CA, Cannon G, Moubarac JC, et al. Ultra-processing. An odd 'appraisal'. Public Health Nutr 2018;21(3):497-501.

27. Machado PP, Steele EM, Levy RB, et al. Ultra-processed foods and recommended intake levels of nutrients linked to non-communicable diseases in Australia: evidence from a nationally representative cross-sectional study. BMJ Open 2019;9(8):e029544.

28. Moubarac JC, Batal M, Louzada ML, et al. Consumption of ultra-processed foods predicts diet quality in Canada. Appetite 2017;108:512-520.

29. Popkin B. El impacto de los alimentos ultraprocesados en la salud. 2030 Alimentación, agricultura y desarrollo rural en América Latina y el Caribe, No. 34. Santiago de Chile: FAO; 2020.

30. Ministerio de Salud -MINSAL-, Gobierno de Chile [Ministry of Health -MINSAL-, Government of Chile]. Ley № 20.606 Sobre la Composición 
Nutricional de los Alimentos y su Publicidad [Law no. 20,606 on nutritional food composition and its advertisment]. 2012;1-2. https://www. minsal.cl/wp-content/uploads/2019/08/EVALUACION-LEY-DE-ALIME NTOS_julio-2019_02.pdf [Accessed October 30, 2021].

31. Instituto Nacional de Estadísticas. Reporte región del Bio-Bío. Available at: https://regiones.ine.cl/biobio/estadisticas\#Estad\%C3\%ADsticas_de_ poblaci\%C3\%B3n

32. Olivares S, Zacarías I, González CG, et al. Proceso de formulación y validación de las guías alimentarias para la población chilena. Rev Chil Nutr 2013;40(3):262-268

33. Olivares S, Zacarías Hasbún I, et al. Diseño y validación de la imagen para la difusión e implementación de las guías alimentarias para la población chilena. Nutr Hosp 2015;32(2):582-589.

34. Landis JR, Koch GG. The measurement of observer agreement for categorical data. Biometrics 1977;33:159-174.

35. Müller R, Büttner P. A critical discussion of intraclass correlation coefficients. Stat Med 1994;13:2465-2476.

36. Martínez-García A, Díez J, Fernández-Escobar C, et al. Adaptation and Evaluation of the Nutrition Environment Measures Survey in Stores to Assess Mediterranean Food Environments (NEMS-S-MED). Int J Environ Res Public Health. 2020;17(19):7031.

37. Herrera JA, Venegas E, Madrigal L. Proporciones de daños mecánicos y su efecto en calidad poscosecha de aguacate 'Hass'. Rev Mex Cienc Agríc 2018:8(spe19):3897-3909.

38. Pierce GE, Drago GK, Ganguly S, et al. Preliminary report on a catalyst derived from induced cells of Rhodococcus rhodochrous strain DAP 96253 that delays the ripening of selected climacteric fruit: bananas, avocados, and peaches. J Ind Microbiol Biotechnol 2011;38:1567.

39. Gittelsohn J, Sharma S. Physical, consumer, and social aspects of measuring the food environment among diverse low-income populations. Am J Prev Med 2009:36(4):S161-S165.

40. Mah CL, Taylor N. Store patterns of availability and price of food and beverage products across a rural region of Newfoundland and Labrador. Can J Public Health 2020;111(2):247-256.

41. Gittelsohn J, Trude ACB, Kim H. Pricing Strategies to Encourage Availability, Purchase, and Consumption of Healthy Foods and Beverages: A Systematic Review. Prev Chronic Dis 2017;14:E107.

42. Mendonça RD, Souza AC, Pimenta AM, et al. Ultra-Processed Food Consumption and the Incidence of Hypertension in a Mediterranean Cohort: The Seguimiento Universidad de Navarra Project. Am J Hypertens 2017;30(4):358-366.

43. Jensen M. Transformation of the food system in Chile: land use change and international trade. Estudios Internacionales 2021;199:61-90.

44. Ministerio de Salud, Subsecretaría de Salud Pública, Gobierno de Chile. Ley 20606 sobre composición nutricional de los alimentos y su publicidad. Boletín. 2012. Available at: https://www.bcn.cl/leychile/navegar? idNorma $=1041570$

45. Ministerio de Salud, Gobierno de Chile. Ley 20869 sobre publicidad de los alimentos. Boletín 13-Nov, 2015. Available at: https://www.bcn.cl/leych ile/navegar?idNorma $=1083792$

\section{Publisher's Note}

Springer Nature remains neutral with regard to jurisdictional claims in published maps and institutional affiliations.

Ready to submit your research? Choose BMC and benefit from:

- fast, convenient online submission

- thorough peer review by experienced researchers in your field

- rapid publication on acceptance

- support for research data, including large and complex data types

- gold Open Access which fosters wider collaboration and increased citations

- maximum visibility for your research: over $100 \mathrm{M}$ website views per year

At $\mathrm{BMC}$, research is always in progress.

Learn more biomedcentral.com/submissions 